\title{
Authentic Learning: A Concept Analysis
}

\author{
Mary Chabeli ${ }^{1}$, Anna Nolte ${ }^{1} \&$ Gugu Ndawo ${ }^{1}$ \\ ${ }^{1}$ Department of Nursing, University of Johannesburg, Auckland Park, South Africa \\ Correspondence: Gugu Ndawo, Department of Nursing, University of Johannesburg, P.O. Box 524, Auckland \\ Park, 2006, South Africa. Tel: 27-11-559 6984.
}

\author{
Received: July 5, 2020 Accepted: December 2, 2020 Online Published: February 15, 2021 \\ doi:10.5539/gjhs.v13n4p12 URL: https://doi.org/10.5539/gjhs.v13n4p12
}

\begin{abstract}
Authentic learning (AL) is a learner-centred approach in which learners co-construct their own knowledge by engaging in and addressing real life problems that demand the use of higher order thinking skills (HOTS), real world resources and tools while thinking and acting like experts. However, AL is a concept that is ambiguous and abstract therefore challenges nurse educators in fully engaging learners in such problems thus limiting their development of HOTS. The purpose of this article was to describe the concept analysis process that was followed to clarify AL, provide conceptual meaning in nursing education, and formulate a theoretical definition using Walker and Avant's eight-step method. Definitions, nature, characteristics and uses of AL were sought and the researchers explored 160 publications which included dictionaries, encyclopaedias, thesauri, conference papers, research reports, journal articles and subject-related literature across multiple disciplines to critically analyse AL. A 17-year period from 1988 to 2015 was used to search several databases. The defining attributes which included antecedents, the process and consequences of $\mathrm{AL}$ emerged. The consequence of $\mathrm{AL}$ in nursing education is a competent, critical, autonomous, independent, lifelong graduate desirable for the $21^{\text {st }}$-century global healthcare system. A theoretical definition of AL was also formulated. The study findings indicated that nurse educators can be assisted to design AL tasks that expose learners to AL thus implications were stated and recommendations were made.
\end{abstract}

Keywords: antecedents, authentic learning, concept analysis, consequence, defining attributes, $21^{\text {st }}$-century graduate

\section{Background}

Authentic learning (AL) is a learner-centred approach in which learners co-construct their own knowledge by engaging in real-life tasks that require higher order thinking skills (HOTS) (Baloyi \& Mtshali, 2018) employed by experts daily. Learners engage in realistic tasks and use real-world resources and tools that provide them opportunities to learn with intention by thinking and acting like experts in order to address real-life problems (Redmond, Davies, Cornally, Adam, Daly, Fegan, \& O'Toole, 2018). The HOTS that are developed become relevant to the real world and can be adapted to any new AL situations encountered in everyday professional life. Thus the HOTS are indispensable in the development of a $21^{\text {st }}$-century graduate who is expected to effectively and successfully solve real-world, complex problems (Luttfi, 2020).

It is of great importance that in an AL situation, realistic problems and their relevance to learners are solved in real communities of practice, outside of classrooms, where real-life integration of learning takes place. Learners are equipped with $21^{\text {st }}$-century cognitive, intrapersonal and interpersonal competencies such as critical thinking, reflective thinking, effective problem solving, rational decision making, communication, collaboration, emotional intelligence, and metacognition. These competencies are critical in dealing with complex global healthcare issues. Based on the findings of this concept analysis, AL is rooted in constructivism and humanism philosophies, motivational, situated learning and experiential learning theories, problem-based learning, and activity-based and participatory learning approaches (Ndawo, 2017).

Many researchers have documented positive outcomes of $\mathrm{AL}$ and authentic assessments (Abelha, Fernandes, Mesquita, Seabra, \& Ferreira-Oliveira, 2020; Baloyi \& Mtshali, 2018; Cremers, Wals, Wesselink, \& Mulder, 2016; Enomoto, 2019; Nyanjom, Goh, \& Yang, 2020; Villarroel, Bloxham, Bruna, Bruna, \& Herrera-Seda, 2018). However, although the outcomes are positive, nurse educators continue to engage learners in the traditional classroom-bound educator-centred approaches, such as whole class teaching, traditional lecturing, direct instruction, demonstrations and assessment (Sewagegn \& Diale, 2020). Within these approaches, learners are 
deemed 'empty vessels' who passively receive knowledge; they are the consumers of information rather than investigators and constructors of their own knowledge. They receive prescriptive assignments, are directed to prescribed textbooks, and they are continually subjected to structured clinical engagements and pen and paper summative assessments. Such directions and prescriptions result in rote learning, lack of comprehension and difficulty in establishing solutions with real-life purposes (Ndawo, 2017).

Nursing serves communities by providing safe, holistic, individualised therapeutic and evidence-based care through critical thinking, rational decision making and creative problem solving (Shaffer, Swan, \& Bouchaud, 2018). In order to realise the science and art of nursing, nurse educators must fully engage learners in this approach by designing AL tasks and authentic assessments that will expose learners to real-life contexts. However, the extensive use of AL as a concept in literature makes it ambiguous and abstract; it is thus challenging for nurse educators to effectively use it, examine its strengths and weaknesses, and envision its unique nature (Turner \& Harder, 2018). Therefore, as an ambiguous and abstract concept, AL needs to be clarified to provide its underlying conceptual meaning.

The clarification will provide a clear and shared understanding among nurse educators which can be useful in directing and guiding nursing education in pursuit of developing learners' HOTS and lifelong learning skills. Learners will be enabled to effectively and successfully deal with and find innovative solutions for the complex challenges of the $21^{\text {st }}$-century global healthcare system. In turn, the radical call that has been sounded for decades for nursing education to produce such a professional nurse will be met (Bvumbwe, \& Mtshali, 2018; Council on Higher Education, 1997, January; Department of Health, 2006; Fawaz, 2018; Ministry of Education, 2001; Pisano, Lange, Berger, \& Hametner, 2015; South African Nursing Council [SANC], 1992a). This clarification will improve nursing research and ultimately nursing practice.

\subsection{Problem Statement}

Ambiguity and lack of clarity of $\mathrm{AL}$ as a concept results in confusion and different interpretations by nurse educators. Its fluid and highly complex nature make the facilitation of learning in an AL situation challenging (Koufidis, Manninen, Nieminen, Wohlin, \& Silé, 2020). It becomes highly impractical for some nurse educators to design authentic tasks and develop innovative pedagogical tools such as authentic assessments. As a result, they believe that they facilitate AL, while they only partially adopt the facilitation of AL methods such as problem-based learning. At the same time, subjecting learners to the traditional lecture method, prescriptive assignments and traditional written examinations with rigid memoranda from textbooks, which do not develop learners' HOTS (Ndawo, 2017). Inauthentic learning confines personal meaning and relevance to learners and leads to difficulty in developing the necessary HOTS for the complex $21^{\text {st }}$-century global healthcare system (Enomoto, 2019; Rowe, 2016). The confusion caused by this concept challenges nurse educators in realising the opportunities and the potential that the AL approach can offer, which results in dire consequences of inauthentic learning. Based on this confusion and its consequences, the researcher responded to a necessity to clarify the meaning of AL for nurse educators by asking: What is the meaning of authentic learning in nursing education?

\subsection{Research Purpose}

This paper sought to clarify the conceptual meaning of AL in nursing education by defining the concept and providing a common understanding.

\section{Research Method}

Walker and Avant's (2019) method of concept analysis was used in analysing AL. This method was considered "classical and traditional" by Tofthagen and Fagerstrøm (in Thompson, 2018) and was chosen because it is the simplest, most comprehensive and systematic method, which render it easier to understand and apply to concepts that are still evolving (Yazdani \& Shokooh, 2018). The eight steps of this method did not need to be and were not employed in sequential order as indicated by Walker and Avant (Thompson, 2018). The eight steps, as they were applied in the analysis of the AL concept, are presented next.

Step 1: Select a concept

$\mathrm{AL}$ in nursing education was selected due to being a concept that is ambiguous and lacked clarity and as a result such learning was not facilitated in the learning environment by some nurse educators. However, it is an important concept since the current trend in education is to respond to complex, real-life problems that learners will encounter in the real world.

Step 2: Determine the purposes of analysis

The first purpose of the analysis was to clarify the conceptual meaning of AL in nursing education by identifying 
the defining attributes of the concept. The second purpose was to formulate a theoretical definition of AL to improve communication of the concept among nurse educators.

\section{Step 3: Identify all uses of the concept}

The researcher explored dictionaries, encyclopaedias, thesauri, conference papers, research reports, journal articles and subject-related literature across multiple disciplines to critically analyse AL (Walker \& Avant, 2019). This literature provided the researcher with rich data, a broader perspective of meaning and vital information needed for meticulous analysis (Denzin \& Lincoln, 2018). The researcher sought only the definitions, nature, characteristics and uses of AL that were available in the literature; therefore, both relevant primary and secondary sources were consulted and included. According to Walker and Avant (2019), to critically analyse the concept, most relevant literature were included to capture all relevant meanings of the concept; this included the majority of disciplines and fields of study such as education, psychology, sociology, engineering, medicine and nursing. Therefore, the EBSCO Host online search platform, the Cumulative Index of Nursing and Allied Health Literature (CINAHL), MEDLINE, Education Resource Information Center (ERIC), Google Scholar, PsycInfo, Index to Dissertations and Theses databases with Boolean operators and an advanced search process were used. Literature with 'authentic', 'authenticity' and 'authentic learning' as title words were retrieved as they were deemed appropriate boundaries to search both primary and secondary sources. The search was not limited to nursing but extended to capture all relevant meanings of the concept.

A total of 5119 publications were retrieved and additional limits in terms of academic journals, conference papers, full text articles with references, adjustments for double entries and English language were placed, which reduced the number of publications to 670. The remaining literature was further excluded as it did not contain the definitions, nature, characteristics and uses of AL. Saturation was reached at 146 sources when the sought information, namely definitions, nature, characteristics and uses of AL, was recurring (Polit \& Beck, 2018). Fourteen (14) definitions were included from dictionaries, thesauri and encyclopaedias from the university's library, yielding a total of 160 publications for concept analysis. The inclusion criteria encompassed literature from the years 1988 to 2015, a 17-year period, to ensure that relevant data and important initial work related to AL was included as countless studies have been conducted on AL. The inclusion criteria for the sources were: literature published in English; papers available in full text; and literature containing only the definitions, nature, characteristics and uses of AL.

Exclusion criteria were: non-English publications, duplicates and irrelevant literature that were excluded on the basis of additional limits, and that did not contain the definitions, nature, characteristics and uses of AL. The inclusion and exclusion criteria were employed as presented on the QUOROM flow chart in Figure 1.

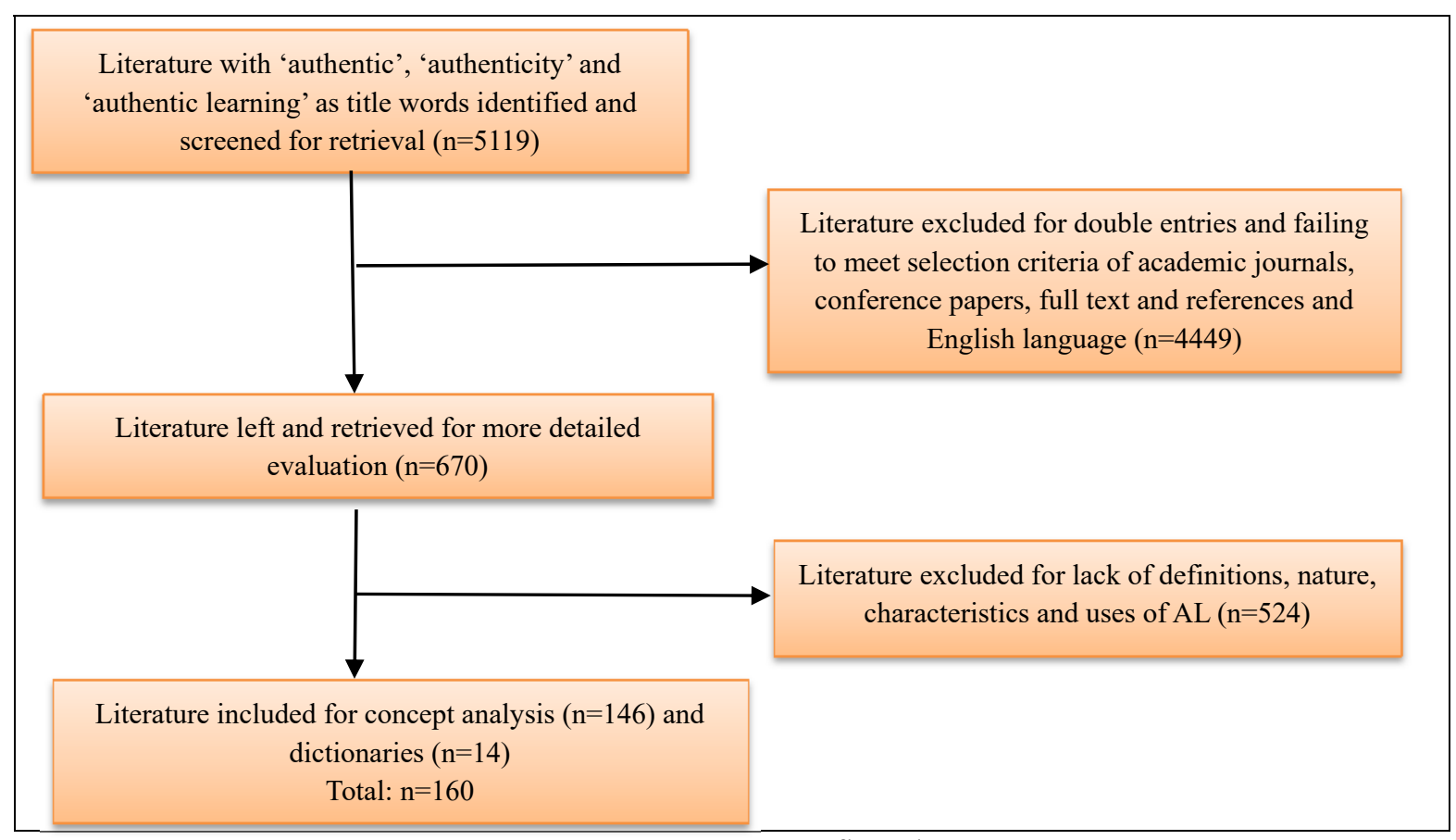

Figure 1. QUOROM flow chart 


\section{Step 4: Determine the defining attributes}

The researcher immersed herself in the definitions, nature, characteristics and uses of AL in a reiterative and repetitive process, and the logical reasoning (Thompson, 2018) used to identify the defining attributes was influenced by the appropriateness and accuracy of the information from the literature. The defining attributes of AL that were extrapolated encompassed engagement in interactive, integrative and constructive approaches to intentional, real-life, meaningful learning activities. These included dialogue, discourse, argumentation, conversation, collaboration, co-operation, research-based activities, higher order thinking, and integration of technology. Metacognitive skills development entailed self-concept; meta-learning; and the ability to make rational decisions and solve complex, real-world, ill-defined problems that are open to multiple perspectives. AL is cyclic in nature.

Step 5: Identify antecedents and consequences

Antecedents are the factors that need to be present for AL to take place (Walker \& Avant, 2019). The identified antecedents were uncertainty, ambiguity, cognitive dissonance, awareness of the lack of knowledge, and Bloom's Revised taxonomy's cognitive and affective domains (Armstrong, 2016). Any occurrences that result because of AL having taken place are called 'consequences' (Walker \& Avant, 2019). The consequence of AL is a competent, critical, autonomous, independent, lifelong graduate desirable for the $21^{\text {st }}$-century global healthcare system.

Step 6: Identify a model case

A model case was identified using a real-life, clinical example to illustrate the defining attributes of AL and they are presented in bold and in italic. They represented the researcher's best understanding of the concept of AL in nursing education using the final results of the concept analysis as indicated in the model case below.

\section{Model case}

A group of six nursing learners chose an authentic task to explore the management of patients with third-degree burns. They chose a patient in the burns unit to complete this task. When they came into contact with the patient they were unsure of what was expected from them (uncertainty). Feeling doubtful and unsure of where to start (ambiguity), their mental discomfort resulted in mental incongruence (cognitive dissonance). Somehow they knew they would be unable to deliver any meaningful care due to a lack of knowledge (awareness of lack of knowledge). They required cognitive and affective qualities and recall of information such as facts, models, formulae and theories to effectively deal with such a patient (remembering). Patience and opening themselves up to learning were important in facilitating the acquisition of new knowledge (receptivity). They needed to know the pathophysiological processes of such injuries to translate, interpret and extrapolate knowledge in order to make sense of their task (understanding). Understanding of knowledge motivated the learners to want to assist the patient (responding). They realised the need to work together to influence their performance positively (interactive), bringing together different ideas into one uniform plan of action (integrative). They built up ideas, thoughts and feelings by making meaningful interpretations, inferences and justifications that shaped their learning (constructive). They realised that all the interventions should be significant and make sense (meaningful) while at the same time the interventions needed to be planned and purposeful (intentional) in a true, genuine situation (real life) [engagement in an interactive, integrative and constructive approach to intentional, real life, meaningful learning]. They thus engaged in discussions and probing without fear (dialogue), using face-to-face interactions and social media in their discussions following a process of reasoning (discourse). They reasoned for and against, weighed evidence, substantiated and examined their points of view and perspectives (argumentation). They exchanged thoughts by talking, questioning and playing games to facilitate their understanding (conversations). They also interacted, worked and shared information, insights, experiences and reflections with individuals such as the patient and the family, global experts in burns, the community leader and members of the multi-disciplinary team involved in the management of this patient such as nurses, physicians, nutritionists, physical and occupational therapists, infection control personnel and psychologists (collaborative, co-operative). Learners thus engaged in a careful systematic search for information and used evidenced-based practice to investigate, discover and engage in a disciplined enquiry while hunting for facts using credible research methods such as meta-analysis to generate solutions (research-based). They engaged in critical thinking, reflective thinking, creativity and innovation thinking (HOTS). They related and integrated the relevant theories, models and formulae into the acquired information (applying), breaking down information into its fundamental elements to examine its elements, then categorising, comparing and contrasting it for better understanding (analysing). They were successful in analysing such information because of mutual trust, respect, willingness, appreciation for each 
other's points of view and believing in themselves (valuing). They engaged in self-assessment of their activities and examined the newly acquired information to determine whether it would work for them in future (evaluating). For successful evaluation they arranged the gathered information into meaningful, systematic and orderly patterns (organisation). The learners demonstrated characteristics of intellectual or cognitive growth by becoming aware of and regulating their own thinking processes to maximise learning (metacognitive skills development). By looking at the likes, dislikes, needs and impressions they had of themselves, they realised how their own 'self' related to the world (self-concept). They developed an ability to plan, execute and evaluate their own learning (meta-learning). They made sensible choices based on the carefully chosen alternatives (rational decision-making). They learned to identify and resolve complicated patients' problems effectively with an open mind (solve complex, real world, ill-defined problems open to multiple perspectives). They utilised the information to construct new information and generate new and unique solutions through synthesis (creating). Moreover, they selected the information and abilities that worked and they made it their own, which they will connect and adapt to new incoming information in the future (internalisation). As a result they acquired the necessary knowledge, skills, values and attitude to provide unique, comprehensive and holistic care to patients with burn injuries (competent). They developed skills and abilities to criticise and appraise information of relevance to improve patients' health (critical). Consequently, they are now able to direct their own actions based on their values and beliefs (autonomous). They have thus become practitioners who are able to make rational decisions without any control from others (independent); and they will continue to learn and improve throughout their lives (lifelong learners) [outcome]. They have realised that due to the dynamic nature of the real life clinical situations, learning is never-ending and they may need to start the authentic learning process again (cyclic).

\section{Step 7: Identify borderline, related and contrary cases (additional cases)}

There was no need to construct borderline and related cases since the model and contrary case provided enough insight to distinguish the concept clearly. A borderline case would have included the following concepts: credible, valid, convincing, faithful, actual, bona fide, indubitable, unquestionable and undoubted. A related case would have included the following concepts: true, genuine and original. The contrary case is constructed and illustrated below, and it is a clear presentation of what $\mathrm{AL}$ is not.

\section{Contrary case}

Nursing students are lectured (uncritical sponges) on a topic of haematuria in class (sterile teaching) and given homework to design a nursing care plan for the invented scenario (fictitious) on this topic. They are expected to do a class presentation the next day. The following month they write a semester test on haematuria (regurgitation and memorisation of facts) where a mix of recall, "true or false" and multiple-choice questions are asked (pen-and-paper assessments that require right and wrong answers; dualistic thinking). A semester mark is then awarded.

\section{Step 8: Define empirical referents}

The following HOTS were identified as empirical referents of AL with their tools for empirical assessment; the tools can be adapted to a specific context, which in case of this article, nursing education. Critical thinking: California Critical Thinking Skills Test (CCTST), the California Critical Thinking Disposition Inventory (CCTDI) (Facione \& Facione, 1992), and the Health Sciences Reasoning Test (HSRT) (HSRT, n.d.). Creative thinking: Torrance's Test of Creative Thinking (TTCT) (Torrance, 1990). Innovation capacities: General Innovation Skills Aptitude Test 2.0 (GISAT2.0) (Conference Board of Canada, 2009). Reflective thinking: Reflective thinking questionnaire, (Kember et al., 2000) and The Groningen Reflection Ability Scale (GRAS) (Aukes, Geertsma, Cohen-Schotanus, Zwierstra, \& Slaets, 2007). Problem-solving skills: Problem Solving Inventory (PSI) (Heppner \& Petersen, 1982). Decision-making skills: Melbourne Decision Making Questionnaire (MDMQ) I-II (Mann, Burnett, Radford, \& Ford, 1997), and Decision Making Style Scale (DMSS) (Scott \& Bruce, 1995). Clinical reasoning skills: The Script Concordance Testing (SCT) (Charlin, Roy, Brailovsky, Goulet, \& van der Vleuten, 2000). Clinical judgment skills: Lasater Clinical Judgment Rubric (LCJR) (Lasater, 2007).

\subsection{Theoretical Validity}

Theoretical validity is the ability of the report to unambiguously describe and interpret a concept (Hayashi, Abib, \& Hoppen, 2019). The researcher explored 160 relevant primary and secondary sources on the definitions, nature, 
characteristics and uses of $\mathrm{AL}$, and determined the meaning of $\mathrm{AL}$ within nursing education. A theoretical definition that displayed the defining attributes of $\mathrm{AL}$ was formulated (the epistemological principle). A model case to illustrate the applicability, relevance and usefulness of the attributes of AL was constructed, and the consequence and empirical referents were clearly identified from concept analysis (the pragmatic principle). AL was consistently and appropriately applied in nursing education (the linguistic principle). The relationship of AL to contrary concepts was shown through a contrary case, and the AL concept held its boundaries; therefore, it was not blurred (the logical principle) (Fontein-Kuipers, de Groot, \& van Staa, 2018).

\section{Findings}

The findings of the concept analysis are illustrated in Figure 2 below that are presented as a conceptual map, which demonstrates the defining attributes under three categories of AL in nursing education as antecedents, the process and the consequence. The theoretical definition of $\mathrm{AL}$ was formulated last. The discussion of the defining attributes of AL follows hereunder.

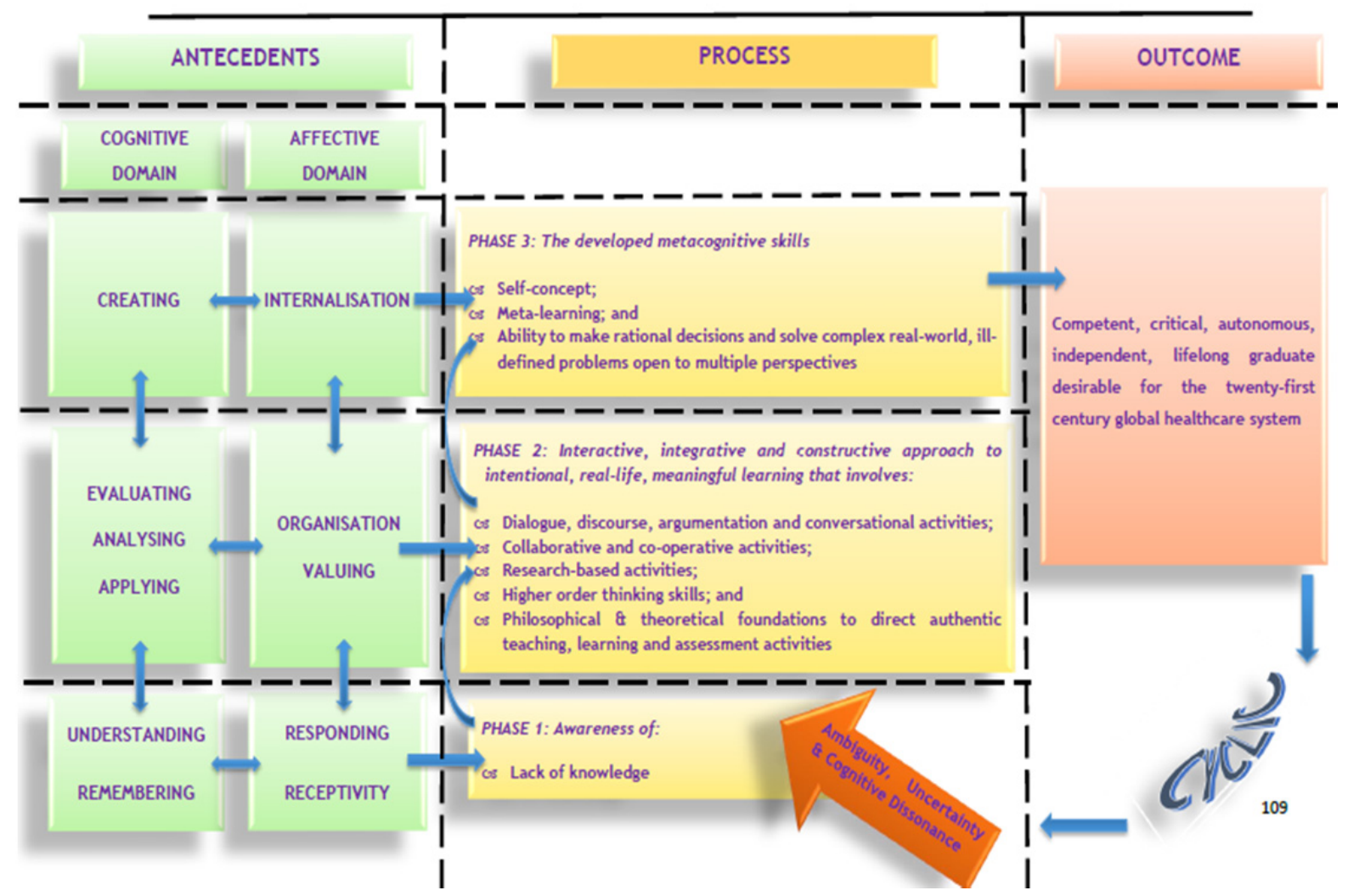

Figure 2. Results of concept analysis of authentic learning: A conceptual map

\section{Discussion}

\subsection{Antecedents}

The state of ambiguity, uncertainty and cognitive dissonance experienced by learners when they receive an AL task, triggers the AL process as learners become aware that they lack knowledge and skills to deal with the task (Koufidis et al., 2020). Ambiguity is a feeling of lacking an appropriate frame of reference to make sense of the complex learning situation, and uncertainty is one's perception of a lack of knowledge (Han, 2016). Cognitive dissonance is the mental discomfort that the learner experiences when new information presented in an $\mathrm{AL}$ situation does not connect with their prior knowledge, resulting in difficulty explaining the situation (Levy, Harmon-Jones, \& Harmon-Jones, 2018). Ambiguity, uncertainty and cognitive dissonance also act as a trigger and lead to a state of awareness of lack of knowledge.

\subsection{Process of $A L$}

When learners enter an AL environment, they become aware that they lack knowledge by asking reflective questions that challenge their comfort zones, such as: Do I have the necessary knowledge to deal with this situation? 
To answer such questions, they need to possess different types of basic knowledge such as contextual, foundational, procedural, conceptual and interdisciplinary knowledge. Knowledge acquisition and remembering the acquired knowledge depends on the receptivity as the lowest affective domain of the learner to pay attention, to be open-minded and willing to learn. To be able to understand, learners take the newly acquired information and translate, interpret and extrapolate it to achieve a meaningful understanding of the information (Haris \& Yusrian, 2019). They respond to this newly acquired information by willingly participating in discussions and sharing such knowledge with fellow learners (Kristiawan, Jumeldi, Ahmad, \& Asvio, 2016).

Learners are now ready to actively engage in an interactive, integrative and constructive approach to intentional, real-life, meaningful learning. The AL approach is interactive because learners collaboratively exchange acquired knowledge and skills through meaningful active participation. It is integrative as learners engage in interdisciplinary co-constructions of knowledge, at the same time improving the knowledge of their own disciplines; this affords them opportunities to solve complex problems using varied disciplinary knowledge (Lestari, Stalmeijer, Widyandana, \& Scherpbier, 2019). It is constructive since a community of learners actively create their own knowledge through engaging willingly with others in social and practical learning environments. The AL approach is intentional in nature and learners experience willingness, intrinsic motivation and a strong need to engage in various cognitive activities to construct knowledge (Redmond et al., 2018). AL cannot occur in a vacuum but in a real-life environment and it facilitates meaningful learning. Within this approach, learners ask themselves reflective questions such as: What learning activities can we employ to facilitate learning about this complex situation? From the concept analysis of AL, the following learning activities emerged: (a) dialogue, discourse, argumentation and conversation; (b) collaboration and co-operation; (c) research-based activities; and d) higher order thinking activities. To facilitate meaningful learning, integrating technology within these activities was highly valued.

(a) Dialogue, discourse, argumentation and conversational activities

Engaging in dialogue and discourse with other learners and experts in the field is achieved through face-to-face and virtual interactions and discussions, video conferencing, blogs, chat spaces and through social media such as Facebook. Learners also engage in argumentation about reasons for and against, weighing of evidence, and they demonstrate methodological presentation of reasoning during debates about the task. As a result, they are exposed to the diverse substantiated points of views of others. They engage in conversations with each other and significant others as they question, brainstorm and play games to facilitate their own understanding and make sense of the AL situation (Ndawo, 2017).

(b) Collaborative and co-operative activities

Learners collaboratively and co-operatively work and interact together in small groups that allow for elaboration and clarification of knowledge and conceptual understanding, while depending on each other to a certain extent to achieve academic goals (Bruce \& Klopper, 2017). Learners' conceptual understanding is nurtured and developed as they relate, connect, analyse, synthesise, discuss, communicate and justify their ideas and thoughts pertaining to the AL situation, such as interdisciplinary problem-based learning (Stentoft, 2017).

\section{(c) Research-based activities}

Research-based activities stimulate learners' interest, curiosity and inquisitiveness and bring about a state of wondering, therefore motivating them to engage in learning activities such as community outreach projects (Kabeel \& Eisa, 2016). They explore, experiment, investigate, discover, and engage in disciplined inquiry. They also create their own knowledge through scientific research processes as they scrutinise the current information and come up with findings which they present to a community of experts for critiquing. They use Google Drive to critique each other's work (Teräs \& Kartoğlu, 2017).

\section{(d) Higher-order thinking activities}

Learners develop the ability to think in an intellectually disciplined manner by challenging the status quo and assumptions, engaging in reflective scepticism and using unconventional approaches to make accurate clinical judgments regarding patient care (critical thinking). They engage in self-dialogue and learn to look back, ponder, meditate, introspect, retrospect, contemplate and deliberate on their learning experiences on electronic journals (e-journals) and portfolios (e-portfolios) to gain new understanding (reflective thinking) (Ndawo, 2017). They link the information that is isolated and unrelated into a unique set of information through ingenuity, imagination, invention and incorporating it with their past experiences (creativity and innovation). They are thus enabled to make astute evidence-based judgments and create evidence-based solutions. Using these HOTS, learners are able to cope with the dynamic, complex problems in the $21^{\text {st }}$-century (Knoff, 2019). 
All these activities are possible by applying and adapting the acquired knowledge through rational decision making and solving complex problems, which is the characteristic of an excellent education. They also critically analyse the collected information by breaking it down for better understanding. Following a critical analysis of information, learners evaluate the acquired knowledge for reliability, validity and trustworthiness. Meaningful conceptual change is produced by upholding values such as mutual trust, respect, readiness to accept others, appreciating other's point of views and patience (valuing). The process also occurs through being objective, flexible, systematic, orderly and consistent, and using reasoning that is well organised (Sulisworo, Maryani, \& Roengsamut, 2017). All these AL activities lead to intellectual growth and maturity, demonstrated by developed metacognitive skills.

Metacognition is an awareness of skills, strategies and resources needed to perform an authentic task effectively, and the ability to use self-regulatory mechanisms to ensure successful completion of such tasks (Kosior, Wall, \& Ferrero, 2019). When learners possess metacognitive skills, they are able to adapt to any complex clinical situation. Metacognition leads to the development of self-concept, meta-learning, as well as an ability to make rational decisions and solve complex, real-world problems open to multiple perspectives. Through self-concept, which includes self-knowledge, self-awareness and self-directed inquiry, learners can regulate their own thoughts and feelings, and this knowledge renders them highly adaptive to varied complex tasks and working across numerous disciplines (Aranha, dos Santos, \& Garcia, 2018). By now, learners' meta-learning is well developed, which is the ability to plan, execute, monitor, evaluate and manage their own learning. They identify and formulate their own academic goals, make their own choices and take control of their academic lives (Ndawo, 2017). With the intellectual growth and maturity that learners display, they are now able to make rational decisions and solve complex problems effectively.

The learners' development of metacognitive skills is influenced by creating and internalisation. Learners engage in the process of creating to demonstrate an advanced conceptual understanding that will bring about unique, evidence-based solutions (Kim, 2019). Learners ask themselves questions such as: Is the information that I have acquired usable in future? If so, do I need to make it part of me to adapt to any challenging clinical situation? (Internalisation).

\subsection{Consequence of $A L$}

The consequence or outcome of AL is a competent, critical, autonomous, independent, lifelong graduate desirable for the $21^{\text {st }}$-century global healthcare system. Learners are competent practitioners who apply their acquired knowledge, empowering skills, pertinent values and positive attitude in practice. They are critical agents who render meticulous care to their patients using their developed critical skills (Hadiati, Kuswanto, Rosana, \& Pramuda, 2019). They safely and effectively carry out their duties in an accountable and responsible manner. They autonomously render complex care that is evidence-based and provide a scientific rationale for their care. They understand their roles as independent, dependent and interdependent practitioners who contribute meaningfully among the members of the interdisciplinary team (Yakusheva \& Weiss, 2017). Within an AL environment, they are developed into lifelong learners who, through applying the well-developed capabilities of lifelong learning skills, can handle ambiguity and uncertainty. They become confident and self-regulating practitioners, engage in logical reasoning, make informed judgments, rational decisions, and subsequently solve complex problems. They are able to respond to the needs of the $21^{\text {st }}$-century global community and can practice and function anywhere in the world. Immersing learners in complex real-world problems familiarises them with global issues that the cultural lens provides, which their indigenous families cannot offer (Rosa, Upvall, Beck, \& Dossey, 2019).

4.4 Cyclic

$\mathrm{AL}$ is cyclic in nature due to the fluid complexity of the global healthcare environment. Therefore, when learners encounter an unfamiliar authentic situation that requires them to solve challenging authentic problems, the AL process starts all over again. They engage in a never-ending knowledge creation process that increases the depth and breadth of the constructed knowledge as they continuously experience reality (Williams, 2016).

\subsection{Theoretical definition}

The theoretical definition was derived from the defining attributes of AL (Walker \& Avant, 2019).

$A L$ is a cyclic learning approach to intentional, real-life, meaningful learning, influenced by a hierarchy of cognitive and affective thinking skills in real life or virtual contexts. It is triggered by uncertainty, ambiguity and cognitive dissonance, bringing about a state of awareness followed by an engagement in interactive, integrative and constructive learning activities; leading to the development of metacognitive skills resulting in a competent, critical, autonomous, independent, lifelong graduate desirable for the $21^{\text {st }}$-century global healthcare system. 


\subsection{Implications for Nursing Education}

In nursing education, clarification of the conceptual meaning of AL assists nurse educators in designing AL tasks that expose learners to liberal education. It further develops learners into $21^{\text {st }}$-century graduates who appreciate diversity and transcultural nursing practice, who are research-oriented, immersed in high and virtual technology, and who engage in integrated learning.

\section{Recommendations}

One limitation that was identified was the lack of personal voices of colleagues in defining AL as a concept, as recommended by Walker and Avant (2019). For further nursing research, it is recommended that the conceptual meaning of AL be explored further using the empirical approach. Findings should be compared and incorporated into the theoretical definition.

A model to facilitate AL in nursing education should be developed using the defining attributes from this concept analysis.

Theories, pedagogical and research tools, such as educational programmes, evaluation instruments and a questionnaire to conduct further research should be developed using the identified defining attributes of AL.

\section{Conclusion}

The purpose of this analysis was to clarify the conceptual meaning of AL in nursing education and to provide a definition of AL using Walker and Avant's eight step method of concept analysis. Therefore, the analysis demonstrated how $\mathrm{AL}$ as a concept was understood within the relevant, existing literature. On the one hand, the identified defining attributes and antecedents provided nurse educators with a lens from which to develop better understanding of AL as a concept and a learning approach and in so doing, will assist them to meaningfully engage with learners in facilitating their learning in the real-world. On the other hand, the results of the process of AL that were obtained provided a frame of reference that can be used to further explore the perceptions of nurse educators and learners on how AL can be facilitated in learner nurses. The clarification of the meaning of AL challenges the innovative facilitation skills of learning to produce desired $21^{\text {st }}$-century graduates who will provide efficient, comprehensive and culture-congruent healthcare globally. Therefore, the findings of this research study demonstrated that nurse educators can be assisted in designing authentic, genuine and real-life tasks that will expose learners to $\mathrm{AL}$ in order to produce such graduates.

\section{Author Contributions}

GN is referred to as a researcher in the paper and was responsible for conducting the research as part of a PhD study, and drafting of the manuscript. MC and AN were the supervisor and co-supervisor, respectively, and both critically revised the article and made conceptual contributions. All authors read and approved the manuscript prior to submission.

Part of this work was a PowerPoint Presentation entitled "Authentic learning: A concept analysis" that was presented and published at a Nursing Education Research Conference 2016, 7-9 April 2016, Washington, DC, USA.

\section{Conflicts of Interest and Source of Funding}

Authors declare that there is no conflicts of interest. This work was part of G Ndawo's PhD study funded by the Thuthuka PhD Track [grant number TTK150706123349]. Similar work which was a PowerPoint Presentation entitled "Authentic learning: A concept analysis" was published at a Nursing Education Research Conference 2016, 7-9 April 2016, Washington, DC, USA.

\section{Competing Interests Statement}

The authors declare that there are no competing or potential conflicts of interest.

\section{References}

Abelha, M., Fernandes, S., Mesquita, D., Seabra, F., \& Ferreira-Oliveira, A. T. (2020). Graduate employability and competence development in higher education-A systematic literature review using PRISMA. Sustainability, 12(15), 5900. https://doi.org/10.3390/su12155900

Aranha, E. A., dos Santos, P. H., \& Garcia, N. A. P. (2018). EDLE: An integrated tool to foster entrepreneurial skills development in engineering education. Educational Technology Research and Development, 66(6), 1571-1599. https://doi.org/10.1007/s11423-018-9624-8

Armstrong, P. (2016). Bloom's Taxonomy. Nashville: Vanderbilt University, The Center for Teaching. Retrieved 
from https://cft.vanderbilt.edu/guides-sub-pages/blooms-taxonomy/

Aukes, L. C., Geertsma, J., Cohen-Schotanus, J., Zwierstra, R. P., \& Slaets, J. P. (2007). The development of a scale to measure personal reflection in medical practice and education. Medical Teacher, 29(2-3), 177-182. https://doi.org/10.1080/01421590701299272

Baloyi, O. B., \& Mtshali, N. G. (2018). A middle-range theory for developing clinical reasoning skills in undergraduate midwifery students. International Journal of Africa Nursing Sciences, 9(2018), 92-104. https://doi.org/10.1016/j.ijans.2018.10.004

Bruce, J. C., \& Klopper, H. C. (2017). Teaching and learning the practice of nursing (6th ed.). Cape Town: Pearson.

Bvumbwe, T., \& Mtshali, N. (2018). Nursing education challenges and solutions in Sub Saharan Africa: An integrative review. BMC Nursing, 17(1), 3. https://doi.org/10.1186/s12912-018-0272-4

Charlin, B., Roy, L., Brailovsky, C., Goulet, F., \& van der Vleuten, C. (2000). The script concordance test: A tool to assess the reflective clinician. Teaching and Learning in Medicine, 12(4), 189-195. https://doi.org/10.1207/S15328015TLM1204_5

Conference Board of Canada. (2009). General Innovation Skills Aptitude Test 2.0 (GISAT2.0). Canada: Centre for Business Innovation.

Cremers, P. H., Wals, A. E., Wesselink, R., \& Mulder, M. (2016). Design principles for hybrid learning configurations at the interface between school and workplace. Learning Environments Research, 19(3), 309-334. https://doi.org/10.1007/s10984-016-9209-6

Denzin, N. K., \& Lincoln, Y. S. (2018). The SAGE handbook of qualitative research (5th ed.). Thousand Oaks, CA: Sage Publication.

Enomoto, A. M. Y. (2019). How transformational leadership can be used in Japanese university classrooms to increase authentic learning, student motivation, and positive learning outcomes (Doctoral dissertation, Northeastern University, Boston, Massachusetts). Retrieved from https://repository.library.northeastern.edu/files/neu:m044wx26s/fulltext.pdf

Facione, P. A., \& Facione, N. C. (1992). The California Critical Thinking Skills Test (2nd ed.). Millbrae: The California Academic Press.

Fawaz, M. A., Hamdan-Mansour, A. M., \& Tassi, A. (2018). Challenges facing nursing education in the advanced healthcare environment. International Journal of Africa Nursing Sciences, 9(2018), 105-110. https://doi.org/10.1016/j.ijans.2018.10.005

Fontein-Kuipers, Y., de Groot, R., \& van Staa, A. (2018). Woman-centered care 2.0: Bringing the concept into focus. European journal of Midwifery, 2(5). https://doi.org/10.18332/ejm/91492

Hadiati, S., Kuswanto, H., Rosana, D., \& Pramuda, A. (2019). The effect of laboratory work style and reasoning with Arduino to improve scientific attitude. International Journal of Instruction, 12(2), 321-336. https://doi.org/10.29333/iji.2019.12221a

Han, P. K. (2016). Uncertainty and ambiguity in health decisions. In M. A. Diefenbach, S. Miller-Halegoua, \& D. J. Bowen (Eds.), Handbook of Health Decision Science (pp. 133-144). New York, NY: Springer.

Haris, F., \& Yusrian, S. (2019). Correlation of E-Learning courses toward nursing students' cognitive skills. IJNP Indonesian Journal of Nursing Practices, 3(2), 92-98. https://doi.org/10.18196/ijnp.3298

Hayashi, Jr, P., Abib, G., \& Hoppen, N. (2019). Validity in qualitative research: A processual approach. The Qualitative Report, 24(1), 98-112. Retrieved from https://nsuworks.nova.edu/tqr/vol24/iss1/8

Health Sciences Reasoning Test (HSRT). (n.d.). Insight assessment. Retrieved from http://www.insightassessment.com/Products/Products-Summary/CriticalThinking-Skills-Tests/Health-Scien ces-Reasoning-Test-HSRT

Heppner, P. P., \& Petersen, C. H. (1982). The development and implications of a personal problem solving inventory. Journal of Counseling Psychology, 29(1), 66-75. https://doi.org/10.1037/0022-0167.29.1.66

Kabeel, A. R., \& Eisa, S. A. E-M. M. (2016). The correlation of critical thinking disposition and approaches to learning among baccalaureate nursing students. Journal of Education and Practice, 7(32), 91-103.

Kember, D., Leung, D. Y. P., Jones, A., Loke, A. Y., McKay, J., Sinclair, K., ... Yeung, E. (2000). Development of a 
questionnaire to measure the level of reflective thinking. Assessment \& Evaluation in Higher Education, 25(4), 381-395. https://doi.org/10.1080/713611442

Kim, H. N. (2019). A conceptual framework for interdisciplinary education in engineering and nursing health informatics. Nurse Education Today, 74(2019), 91-93. https://doi.org/10.1016/j.nedt.2018.12.010

Knoff, C. R. (2019). A call for nurses to embrace their innovative spirit. OJIN: The Online Journal of Issues in Nursing, 24(1). https://doi.org/10.3912/OJIN.Vol24 No01PPT48

Kosior, K., Wall, T., \& Ferrero, S. (2019). The role of metacognition in teaching clinical reasoning: Theory to practice. Education in the Health Professions, 2(2), 108-114. https://doi.org/10.4103/EHP.EHP_14_19

Koufidis, C., Manninen, K., Nieminen, J., Wohlin, M., \& Silé, C. (2020). Grounding judgment in context: A conceptual learning model of clinical reasoning. Medical Education, 2020(00), 1-10. https://doi.org/10.1111/medu.14222

Kristiawan, M., Jumeldi, A., Ahmad, S., \& Asvio, N. (2016). The implementation of affective assessment for Islamic Education in high school 1 Pariangan. Research Journal of Social Sciences, 9(4), 1-8. https://doi.org/10.31219/osf.io/a76y4

Lasater, K. (2007). Clinical judgment development: Using simulation to create a rubric. Journal of Nursing Education, 46(11), 496-503. https://doi.org/10.3928/01484834-20071101-04

Lestari, E., Stalmeijer, R. E., Widyandana, D., \& Scherpbier, A. (2019). Does PBL deliver constructive collaboration for students in interprofessional tutorial groups? BMC Medical Education, 19(1), 360. https://doi.org/10.1186/s12909-019-1802-9

Levy, N., Harmon-Jones, C., \& Harmon-Jones, E. (2018). Dissonance and discomfort: Does a simple cognitive inconsistency evoke a negative affective state? Motivation Science, 4(2), 95-108. https://doi.org/10.1037/mot0000079

Luttfi I. K. (2020). The importance of implementing authentic teaching and learning techniques in medical school. International Journal of Medical Science and Education, 7(4), 5-9. Retrieved from http://www.ijmse.com/uploads/1/4/0/3/14032141/ijmse2020_7_4_5-9.pdf

Mann, L., Burnett, P., Radford, M., \& Ford, S. (1997). The Melbourne Decision Making Questionnaire: An instrument for measuring patterns for coping with decisional conflict. Journal of Behavioral Decision Making, 10(1), 1-19. https://doi.org/10.1002/(SICI)1099-0771(199703)10:1<1::AIDBDM242>3.0.CO;2-X

Ndawo, M. G. (2017). A model to facilitate authentic learning in learner nurses at a higher education institution (Doctoral dissertation, University of Johannesburg, Auckland Park, South Africa). Retrieved from http://hdl.handle.net/10210/246626

Nyanjom, J., Goh, E., \& Yang, E. C. L. (2020). Integrating authentic assessment tasks in work integrated learning hospitality internships. Journal of Vocational Education \& Training, (2020), 1-23. https://doi.org/10.1080/13636820.2020.1841821

Pisano, U., Lange, L., Berger, G., \& Hametner, M. (2015). The Sustainable Development Goals (SDGs) and their impact on the European SD governance framework: Preparing for the post-2015 agenda. ESDN Quarterly Report \# 35. Vienna, Austria: European Sustainable Development Network ESDN.

Polit, D. F., \& Beck, C. T. (2018). Essentials of nursing research: Appraising evidence for nursing practice (9th ed.). Philadelphia: Lippincott Williams \& Wilkins.

Redmond, C., Davies, C., Cornally, D., Adam, E., Daly, O., Fegan, M., \& O’Toole, M. (2018). Using reusable learning objects (RLOs) in wound care education: Undergraduate student nurse's evaluation of their learning gain. Nurse Education Today, 60(2018), 3-10. https://doi.org/10.1016/j.nedt.2017.09.014

Republic of South Africa. Council on Higher Education. (1997, January). The Higher Education Act, Act no. 101 of 1997, as amended. Pretoria: Author.

Republic of South Africa. Department of Health. (2006). National Human Resources for Health Plan. Pretoria: Government Printers.

Republic of South Africa. Ministry of Education. (2001). The National Plan for Higher Education. Pretoria: Government Printers.

Rosa, W. E., Upvall, M. J., Beck, D. M., \& Dossey, B. M. (2019). Nursing and sustainable development: Furthering the global agenda in uncertain times. OJIN: The Online Journal of Issues in Nursing, 24(2), 
Manuscript \#1. https://doi.org/10.3912/OJIN.Vol24No02Man01

Rowe, M. (2016). Developing graduate attributes in an open online course. British Journal of Educational Technology, 47(5), 873-882. https://doi.org/10.1111/bjet.12484

Scott, S. G., \& Bruce, R. A. (1995). Decision-making style: The development and assessment of a new measure. Educational and Psychological Measurement, 55(5), 818-831. https://oi.org/10.1177/ 0013164495055005017

Sewagegn, A. A., \& Diale, B. M. (2020). Authentic assessment as a tool to enhance student learning in a higher education institution: Implication for student competency. In E. Railean (Ed.), Assessment, Testing, and Measurement Strategies in Global Higher Education (pp. 256-271). IGI Global.

Shaffer, K., Swan, B. A., \& Bouchaud, M. (2018). Designing a new model for clinical education: An innovative approach. Nurse Educator, 43(3), 145-148. https://doi.org/10.1097/NNE.0000000000000468

South African Nursing Council. (1992a). The philosophy and policy of the South African Nursing Council with regard to professional nursing education. Pretoria: Author.

Stentoft, D. (2017). From saying to doing interdisciplinary learning: Is problem-based learning the answer? Active Learning in Higher Education, 18(1), 51-61. https://doi.org/10.1177/1469787417693510

Sulisworo, D., Maryani, I., \& Roengsamut, Z. (2017). Affective characteristics analysis: A comparative study between elementary school of Indonesia and Thailand. Proceedings of the fourth Asia-Pacific Education Conference (AECON), 8-9 October 2017. Indonesia: Universitas Muhammadiyah Purwokerto. Retrieved from http://creativecommons.org/licenses/by-nc/4.0/

Teräs, H., \& Kartoğlu, Ü. (2017). Authentic learning with technology for professional development in vaccine management. Australasian Journal of Educational Technology, 34(3), 15-29. https://doi.org/10.14742/AJET.2815

Thompson, C. J. (2018). Commonly used concept analysis methods in nursing: An introduction to Walker and Avant's 8-Step method [Web Log Post]. Retrieved from https://nursing educationexpert.com/concept-analysis-methods-walker-avant.

Torrance, E. P. (1990). Torrance test of creative thinking. Manual for scoring and interpreting results. Verbal, Forms $A$ and B. Bensenville, IL: Scholastic Testing Service.

Turner, S., \& Harder, N. (2018). Psychological safe environment: A concept analysis. Clinical Simulation in Nursing, 18, 47-55. https://doi.org/10.1016/j.ecns. 2018. 02.004

Villarroel, V., Bloxham, S., Bruna, D., Bruna, C., \& Herrera-Seda, C. (2018). Authentic assessment: Creating a blueprint for course design. Assessment \& Evaluation in Higher Education, 43(5), 840-854. https://doi.org/10.1080/02602938.2017.1412396

Walker, L. O., \& Avant, K. C. (2019). Strategies for theory construction in nursing (6th ed.). New York: Pearson.

Williams, D. (2016). Creating an assessment and feedback strategy for problem based learning chemistry courses. Student Engagement in Higher Education Journal, 1(1), 1-13. Retrieved from https://sehej.raise-network.com/raise/article/view/391

Yakusheva, O., \& Weiss, M. (2017). Rankings matter: Nurse graduates from higher-ranked institutions have higher productivity. BMC Health Services Research, 17(1), 134-141. https://doi.org/10.1186/s12913-017-2074-x

Yazdani, S., \& Shokooh, F. (2018). Defining doctorateness: A concept analysis. International Journal of Doctoral Studies, 13, 31-48. https://doi.org/10.28945/3939

\section{Copyrights}

Copyright for this article is retained by the author(s), with first publication rights granted to the journal.

This is an open-access article distributed under the terms and conditions of the Creative Commons Attribution license (http://creativecommons.org/licenses/by/4.0/). 